\title{
A Computational Flame Length Methodology for Propane Jet Fires
}

\author{
P.S. Cumber ${ }^{1 *}$ and M. Spearpoint ${ }^{* *}$ \\ Heriot-Watt University* \\ School of Engineering and Physical sciences \\ Riccarton Campus \\ Edinburgh \\ United Kingdom \\ Dept of Civil Engineering ${ }^{* *}$ \\ University of Canterbury \\ Private Bag 4800 \\ Christchurch 8020 \\ New Zealand
}

\begin{abstract}
This paper presents a flame length methodology that mimics the human eye or camera using a CFD framework to calculate the flame structure. A parabolic flow model which accounts for turbulent combustion, soot kinetics and visible radiation distribution is extended to predict both rim-stabilised and lifted jet fires. The model is calibrated using a selected set of jet fire experiments and then validated against a wider range of data. Good agreement over a range of scales is demonstrated particularly when taking the degree of repeatability of the experiments into account. The flame length prediction is found to be insensitive to receiver location so long as the receiver is one or more flame lengths from the fire.
\end{abstract}

KEYWORDS: Flame length, lifted jet fires, parabolic flow model, combustion, radiation heat transfer

\footnotetext{
${ }^{1}$ Corresponding author: E-Mail Address p.s.cumber@hw.ac.uk
} Phone: $01314513532 ; \quad$ Fax : 01314513129 


\section{Nomenclature}

\begin{tabular}{|c|c|}
\hline$c_{p, i}$ & Specific heat of species $\mathrm{i}$ \\
\hline$C_{s, 1}, C_{s, 2}$ & Calibration constants in strain rate models \\
\hline$D$ & Nozzle diameter \\
\hline$f$ & Mixture fraction or frequency \\
\hline$f^{\prime 2}$ & Variance of mixture fraction \\
\hline$f_{L}$ & Flame length \\
\hline$f_{L, B}$ & Flame length of a buoyancy dominated fire \\
\hline$f_{L, M}$ & Flame length of a jet fire \\
\hline $\mathrm{Fr}$ & Froude number \\
\hline$f_{\text {view }}$ & View factor \\
\hline$H_{f u}$ & Heat of combustion \\
\hline$I_{\lambda}$ & Spectral intensity \\
\hline$I_{\lambda, b}$ & Black body spectral intensity \\
\hline$I_{\text {vis }}$ & Visible radiation intensity \\
\hline$k$ & Turbulence kinetic energy \\
\hline$K_{\lambda}$ & Spectral absorption coefficient \\
\hline$l_{H}$ & Lift-off height \\
\hline$\dot{m}$ & Mass flow rate \\
\hline$M_{w, i}$ & Molecular weight of species i \\
\hline$P_{b}$ & Probability of burning \\
\hline$P_{b u r n}$ & Composite probability of burning \\
\hline$P_{d}$ & Probability of burning relating to the location of the fluctuating flame base \\
\hline$\dot{Q}$ & Heat release rate \\
\hline$q_{\text {f,rec }}$ & Radiation heat flux to a receiver \\
\hline$r$ & Radial co-ordinate or stoichiometric ratio on a mass basis \\
\hline Ri & Richardson number \\
\hline$R_{M}$ & Ratio of momentum fluxes \\
\hline$S$ & Strain rate or distance co-ordinate along a characteristic ray \\
\hline$s_{v f}$ & Soot volume fraction \\
\hline$T$ & Temperature \\
\hline
\end{tabular}


$T_{f}$

$U_{0}$

$X, Y$

$Y_{i}$

$Y_{i, \text { yield }}$

Z

Greek Symbols

$\beta$

$\Delta h$

$\varepsilon$

$\varphi$

$\varphi_{b}$

$\varphi_{m}$

$\varphi_{\text {Ray }}, \theta_{\text {Ray }}$

$\lambda$

$v_{l}$

$\rho$

$\sigma$

$\psi$

Subscripts:

$\begin{array}{ll}\text { adia } & \text { Adiabatic property } \\ \text { amb } & \text { Ambient value } \\ f u & \text { Fuel property } \\ \text { mix } & \text { Mixture property } \\ \text { prod } & \text { Combustion products property } \\ q & \text { Quench value } \\ \text { Ray } & \text { Characteristic ray property } \\ \text { st } & \text { Property at stoichiometric conditions } \\ 0 & \text { Initial condition or source condition }\end{array}$

Flame length parameter defined in (9) or a probability density function Enthalpy perturbation

Dissipation rate of turbulence kinetic energy or emissivity

Generic flow variable

Burning flamelet

Isothermal mixing flamelet

Ray orientation expressed in spherical co-ordinates

Wave length

Kinematic viscosity

Density

Stefan Boltzmann constant

Flame length parameter, equation (8) 
Over bars

Reynolds averaged quantity

Favre averaged quantity 


\section{Introduction}

When considering the safety of a high-pressure system processing a flammable material a typical scenario that must be considered is the possibility of an accidental leak that finds a source of ignition. This produces a jet fire characterised by a high momentum source with a flame trajectory in the near field determined by the orientation of the gas leak, further downstream the flame trajectory is modified by the atmospheric boundary layer or the jet fire might impinge on another part of the plant such as a storage vessel, [1]. Jet fires are of particular concern as they represent the worst case for a storage vessel, [2]. Therefore the potential for escalation, where a relatively small jet fire impinging on a storage vessel ultimately leads to vessel failure and a very much larger incident, is a real possibility. A safety engineer when assessing the hazard presented by a jet fire is interested in the flame trajectory, flame length and heat transfer to the surrounding plant and personnel. The flame length is of particular interest as given the flame length appropriate separation distances between equipment and separation distances between plant and the site boundary can be specified.

Research activity in this area has focussed for the most part on identifying the most important dimensionless groups and the development of flame length correlations. Heskestad, [3] extended his buoyant flame correlation to jet fires,

$$
\begin{aligned}
& \frac{f_{L, B}}{D}=15.6 N^{1 / 5}-1.02 \\
& N=\frac{c_{p} T_{a m b}}{g \rho_{a m b}^{2}\left(H_{f u} / r\right)^{3}} \frac{\dot{Q}^{2}}{D^{5}}
\end{aligned}
$$

by introducing a ratio of momentum fluxes $R_{M}$, [4] the ratio of the source momentum to the total momentum, including that due to buoyancy,

$$
R_{M}=\frac{\dot{m}_{0} U_{0}}{\int_{0}^{\infty} \rho u^{2} 2 \pi r d r}
$$

which after some simplification gives the jet fire correlation,

$$
\frac{f_{L, M}}{D}=\left(15.6 N^{1 / 5}-1.02\right) R_{M}=\left(15.6 N^{1 / 5}-1.02\right) 0.117 \frac{\rho_{a m b}}{\rho_{0}} \frac{1}{r^{2}} N^{2 / 5}
$$

where $r$ is the stoichiometric ratio. The above is valid for

$$
\mathrm{R}_{\mathrm{M}}>0.1
$$


The dimensionless group $N$ relates to the dimensionless heat release rate, $\dot{Q}^{*}$, sometimes called the fire Froude Number by the equation,

$$
N=\left(\frac{r c_{p} T_{a m b}}{H_{f u}}\right)^{3} \dot{Q}^{* 2}
$$

Becker and Liang, [5] choose to correlate their flame length measurements using a Richardson number,

$$
R i^{1 / 3}=\xi_{L}=\left(\frac{g}{D^{2} \frac{\rho_{0}}{\rho_{a m b}} U_{0}^{2}}\right)^{1 / 3} f_{L}
$$

and a parameter, $\psi$

$$
\psi=\frac{D\left(\frac{\rho_{0}}{\rho_{a m b}}\right)^{0.5} \beta}{f_{L} m_{f u, s t}}
$$

where,

$$
\beta=\left(\frac{M_{w, a i r} T_{a d i a, s t}}{M_{w, p r o d} T_{a m b}}\right)^{0.5}
$$

For propane $\beta$ is approximately 2.8, [5]. Using $\psi$ and $\xi_{L}$ Becker and Liang showed their flame length measurements collapsed onto the curve,

$$
\psi=0.18+0.022 \xi_{L}
$$

for

$$
1<\xi_{L}<20
$$

provided the Reynolds number at the flame tip was sufficiently high. Kalghatgi, [6] used a similar approach to fit his flame length measurements to get a slightly different correlation,

$$
\psi=0.2+0.024 \xi_{L}
$$


A third correlation for the flame length in the high momentum limit derived by Hawthorne et al., [7] and given in Drysdale, [8] is dependent on the ratio of the flame temperature to the surrounding air temperature, and the flame stoichiometry.

This range of correlations is due in part to the differences in how the flame length is measured or defined. Kalghatgi, [6] for example used a film speed of 1/30 sec and averaged three images to calculate the mean flame length; whereas Sugawa and Sakai, [9] measured the flame height using a video system, averaging ninety images. Another issue is retinal retention of instantaneous flame images in averaging of rapidly fluctuating flames. Typical pulsation frequencies are approximated by the relation,

$$
f=47.4 D^{-0.5}
$$

where $f$ is in $\mathrm{Hz}$ and $D$ is in $\mathrm{mm}$, [4]. Frequencies higher than $10 \mathrm{~Hz}$ can induce retinal retention. Therefore based on (13), jet fires with a diameter of less than $23 \mathrm{~mm}$, induce retinal retention that would tend to overestimate mean flame lengths based on visual observation. A further consideration is flame length correlations derived from laboratory-scale jet fires are not applicable to larger fires in the open air, as the atmospheric boundary layer even at low wind speeds can affect the observed flame length tending to reduce it. Heskestad reports that the open air jet flames of Sonja and Hustad, [10] are not well predicted by the correlation (4) due to the influence of the atmospheric boundary layer. Further evidence of the discrepancy of flame length correlations applied to full scale flames is given by Cook et al., [11] where measured flame lengths for a sonic natural gas jet fire field trial are of the order of $200-400 \%$ longer than Brzustowski and Sommer's correlation predicts, [12].

To overcome the limitations of measuring the visible flame length alternative approaches based on more objective criteria have been derived. The term chemical flame height was proposed by Hawthorne et al., [7] to distinguish it from the visible flame height. Hawthorne et al., [7] defined the chemical flame height as the axial location of $99 \%$ complete combustion. Hottel, [13] defined the chemical flame height as the axial location where the ratio of $\mathrm{CO}$ to $\mathrm{CO}_{2}$ was 0.15 . Wade and Gore, [14] defined the chemical flame height as the distance to where the fuel mole fraction dropped to 0.0005 on the axis. Ideally the chemical and visible flame height should be strongly correlated, however one of Wade and Gore's, [14] findings was that for their definition of flame height the chemical and visible flame height did not scale in the same way with flow 
rate. All of the above definitions have a certain arbitrariness or are proposed on the basis of limitations of the concentration measurement equipment available to the researchers. Newman and Wieczorek, [15] provided a further definition of the chemical flame height based on the concept of species yield for $\mathrm{CO}$ and $\mathrm{CO}_{2}$ from a well ventilated fire. For given specie $i$ the yield is defined as,

$$
Y_{i, \text { yield }}=\frac{X_{i} \dot{m}_{T} M_{w, i}}{\dot{m}_{0} M_{w, \text { mix }}}
$$

where $X_{i}$ is the mole fraction of species $i$, and $\dot{m}_{T}$ is the total mass flow rate. For a propane fire the well ventilated fire limit is,

$$
\frac{Y_{\mathrm{CO}, \text { yield }}}{Y_{\mathrm{CO}_{2}, \text { yield }}}=0.002
$$

Newman and Wieczorek, [15] showed that this definition of chemical flame height is in reasonable agreement with Heskestad's correlation, (1) applied to Orloff et al's., [16] data.

In this article an alternative approach to estimating flame lengths is presented. Rather than deriving correlations using dimensionless groups or some measure of combustion, a flame length methodology based on a Computational Fluid Dynamics (CFD) representation of the flame structure is considered. The flame length methodology is presented and demonstrated for propane jet fires, although its extension to other fuels and types of fire is straight forward.

\section{Flame length methodology}

In fire models with a CFD framework the flame length is not generally a direct output of the model and must be inferred in some way. A common approach is to assume a temperature value delineates the visible portion of the flame. For example Fairweather et al., [17] and Cook et al., [18] using CFD and a phenomenological approach respectively to predict the flame structure, used a threshold value of $1400 \mathrm{~K}$ for field-scale natural gas jet fires, whereas Fairweather et al., [19] used a value of $1200 \mathrm{~K}$ for laboratory-scale natural gas jet fires. A $200 \mathrm{~K}$ change in axial temperature gives a difference in flame length of the order of $20-25 \%$. There is some theoretical foundation for using temperature to infer flame lengths, as the radiation heat flux to a given receiver can be approximated by the relation,

$$
q_{f, \text { rec }}=f_{\text {view }} \varepsilon \sigma T_{f}^{4}
$$


assuming grey emission, [20] where $f_{\text {view }}$ is a view factor, $\varepsilon$ is the flame emissivity, $\sigma$ is the Stefan Boltzmann constant and $T_{f}$ is a characteristic flame temperature. The non-linear dependence on temperature suggests that temperature would be a good marker for changes in received radiation heat flux. The problem is the thermal radiation is also dependent on soot concentration and participating gas species concentrations through the flame emissivity term, $\varepsilon$. In the examples cited above changing the scale of the jet fire from laboratory-scale to field-scale increased the residence time of the fire, increasing the soot levels, thus requiring a different temperature to infer the flame length. Changing the fuel and background radiation levels will also affect the temperature vs. visible flame envelope dependence.

The flame length methodology described below essentially mimics how a camera or human eye senses a fire, that is the receiver senses the radiation intensity field given off by the incandescent soot particles and participating species within the flame envelope.

The flame length methodology can be broken down into the following steps.

- $\quad$ Calculate the jet flame structure using a CFD model

- Specify the camera location and orientation

- Calculate the intensity field incident on the camera lens

- $\quad$ Project the incident intensity field back onto a plane through the fire perpendicular to the camera

- Infer the flame length from the projected intensity field

Before presenting further details of the methodology a number of important issues must be considered. The use of a CFD model to supply the flame structure is a requirement of the methodology, but any model will do provided it is sufficiently accurate. In the following section the mathematical basis of the computational model used in this article is presented. The second issue is the human eye and different camera technologies respond to radiant intensity in slightly different ways that has a second order influence on the perceived flame height. This is due to the significant dynamic range of a fire; that is the ratio of the brightest to the darkest recordable part of an image is large. Considering a single lens reflex camera the perceived flame profile is sensitive to the film speed and shutter speed. If the shutter speed is too slow then the film is overexposed and the image is more representative of the maximum flame height than an 
instantaneous image of the flame. When using digital technology to capture images of fires the situation is further complicated as there are a number of features of this type of camera that can be used to avoid overexposure but make the quantitative analysis of images difficult. In digital cameras the equivalent of overexposure occurs when pixels become saturated and the radiant energy leaks into surrounding pixels, this is termed blooming, [21] and results in white streaks on the image. To overcome this problem many digital cameras modify the incoming intensity field using a technique called gamma correction. Gamma correction alters the image in a highly non-linear way [21] making it difficult to do a quantitative analysis of the image intensity field. Many manufactures of digital cameras do not publish details of the gamma correction technique they have implemented; however in some cameras this process can be removed. Some of the features discussed above can be incorporated into the flame length methodology, for example pictures of a flame taken in the dark to improve the contrast can be modelled by adjusting the background radiation levels in the model. However many of the issues discussed above cannot easily be included in a computational flame length methodology and makes the quantitative assessment of the measured intensity field difficult. In the context of flame length measurement, the complexities of camera technologies discussed above have a second order effect on the perceived visible flame envelope. This is because the flame length methodology relies on using a threshold intensity to determine the flame length and because of the nonlinear dependence on temperature it is relatively insensitive to the intensity value used. This is demonstrated below.

\section{Mathematical model}

The first step in the flame length methodology is to calculate the fire structure. For free jet fires it has been shown that the boundary layer equations formulated for high speed shear flows give a reasonable representation of the fire structure. The basis of the model used in this study is the parabolised Favre averaged Navier Stokes equations in an axi-symmetric co-ordinate system. The system is closed using a variant of the $k-\varepsilon$ turbulence model. The version of the $k-\varepsilon$ turbulence model implemented includes a modification to take account of the round jet/ plane jet anomaly, [22] where the spreading rate of round jets tends to be over predicted by the 'standard' version of the turbulence model. This is a well known limitation of most two equation turbulence models and $2^{\text {nd }}$ moment closure models unless some modification is introduced to account for the reduced spreading rate. Indeed the $2^{\text {nd }}$ moment closure model of Jones and Mussonge [23] was also applied to the jet fires considered here with little or no improvement. 
The modification to the $k-\varepsilon$ model introduced is due to Morse, [24] and has been used successfully in previous rim-stabilised fire simulations, [24]. The axi-symmetric correction is used here as it gives an appropriate balance between model complexity and predictive capability. In addition a further modification to the turbulence model to account for buoyancy induced turbulence was implemented, [25] but ultimately was rejected as the improvement in the mean temperature field was marginal at best.

\subsection{Turbulent combustion model}

In previous free jet fire simulations using the parabolised Navier Stokes equations, application was restricted to rim-stabilised jet fires. To extend the range of measurements available for model validation the jet fire model has been extended to predict lifted jet fires. A variant of Sanders and Lamers, [26] lifted jet fire model based on flamelet quenching and a simple model for the strain rate has been implemented. How the numerical implementation of the parabolised Navier Stokes equations has been extended to include this phenomenon will be considered below. Elements of Sanders and Lamers lifted jet fire model are presented below for completeness and to highlight a number of important differences from their original formulation. The turbulent combustion model is a laminar flamelet combustion model, with two flamelet libraries, one for combustion and the other for isothermal mixing. Combustion is assumed to be infinitely fast with a prescribed probability density function (pdf), a $\beta$ function, [19]. The shape of the $\beta$ function at any spatial location is determined by a conserved scalar, the mixture fraction $f$ and its variance $f^{\prime \prime}$, which are calculated using modelled transport equations, [27]. The combusting flamelet is calculated using a laminar counter flow non-premixed combustion simulation using a detailed kinetic scheme at a strain rate of $90 \mathrm{sec}^{-1}$, [27]. Any mean property can be calculated as a weighted average of the burning and isothermal mixing flamelet weighted by the pdf and integrated over instantaneous mixture fraction space,

$$
\widetilde{\varphi}=P_{d} P_{b} \int_{0}^{1} P(f) \varphi_{b}(f) d f+\left(1-P_{d} P_{b}\right) \int_{0}^{1} P(f) \varphi_{m}(f) d f
$$

where $P_{b}$ is a probability of burning defined below and $P_{d}$ is a probability that the axial location is above the fluctuating flame base.

$$
P_{d}=\int_{0}^{\infty} P_{\text {base }}\left(z>l_{H}\right) d l_{H}
$$


Sanders and Lamers prescribe the pdf for the location of the instantaneous flame base, $l_{H}$ to have a triangular shape, the apex located at the mean lift-off height and the base of the triangle is taken to be five diameters. It should be noted that this is an assumption of convenience rather than one based on observation. However a sensitivity study has shown that the overall flame structure is insensitive to this aspect of the model, [26]. The mean density and mean adiabatic temperature are given by the relations,

$$
\begin{aligned}
& \bar{\rho}=\left[\frac{P_{d} P_{b}}{\int_{0}^{1} P(f) \rho_{b}(f) d f}+\frac{1-P_{d} P_{b}}{\int_{0}^{1} P(f) \rho_{m}(f) d f}\right]^{-1} \\
& \bar{T}_{\text {adia }}=P_{d} P_{b} \bar{\rho}_{b} \int_{0}^{1} P(f) \frac{T_{b}(f)}{\rho_{b}(f)} d f+\left(1-P_{d} P_{b}\right) \bar{\rho}_{m} \int_{0}^{1} P(f) \frac{T_{m}(f)}{\rho_{m}(f)} d f
\end{aligned}
$$

To account for radiation heat loss a transport equation for a specific enthalpy perturbation is solved, where radiation heat loss is introduced using the optically thin approximation, [20]. This approach has been used successfully for other computational studies [27, 28]. The mean temperature is then calculated as,

$$
\bar{T}=\bar{T}_{\text {adia }}-\frac{\Delta h}{\sum_{i} Y_{i} c_{p, i}}
$$

$Y_{i}$ is the mass fraction of species $i$ and the specific heat at constant pressure, $c_{p, i}$ is evaluated from curve fits in temperature to JANNAF thermodynamic property tables for each species, [29]. To close the system the probability of burning and the mean lift-off height must be modelled. The probability of burning is given by,

$$
P_{b}=\int_{0}^{s_{q}} P(s) d s
$$

$s$ is the strain rate, $s_{q}$ is the quenching strain rate and $P(s)$ is a quasi Gaussian pdf for the strain rate. The strain rate can either be taken to be the strain rate of the small-scale turbulence,

$$
s=C_{s, 1}\left(\frac{\varepsilon}{2 v_{l}}\right)^{1 / 2}
$$

or the strain rate of the large-scale turbulence

$$
s=C_{s, 2} \frac{\varepsilon}{k}
$$


where $C_{s, 1}$ and $C_{s, 2}$ are calibration constants. The mean lift-off height is prescribed using percolation theory, [30] and the probability of burning on the stoichiometric contour, see Sanders and Lamers, [26] for more details of the lift-off model.

As stated above the combustion model implemented is the one proposed by Sanders and Lamers, with some crucial differences. It is therefore of interest to consider the differences between the mathematical models described above and Sanders and Lamers approach. The main differences are the model described above includes radiation heat loss via the specific enthalpy perturbation transport equation and the turbulence model implemented accounts for the round jet/plane jet anomaly, [22]. These differences in model basis modify the predicted mean temperature field, and the turbulence fields. There is some evidence for the over prediction of the spreading rate by Sanders and Lamers model, Figure 2 in [26] where the predicted radial position of the stoichiometric concentration is compared with Horch's data [31]. Good agreement is exhibited between Sanders and Lamers model and Horch's measurements for the first 20 diameters after which the agreement deteriorates due to too much mixing.

These differences in fire structure although seemingly minor points of detail ultimately lead to different conclusions with respect to the suitability of the different strain rate models (23) and (24). Sanders and Lamers based on an isothermal jet calibration concluded the small-scale strain rate model to be the superior of the two with respect to predicting the lift-off heights in methane jet fires; however in a recent paper Cumber and Spearpoint, [32] demonstrated that the largescale strain rate model gave a better calibration against Wittmer's lift-off measurements, [33] the data used by Sanders and Lamers. Further studies not reported here, comparing Kalghatgi's liftoff height measurements [6] with the predicted lift-off height using the two strain rate models, for a range of methane and propane jet fires further confirmed the superiority of the large-scale strain rate model.

\subsection{Soot modelling}

Lindstedt's two equation soot model, $[17,28]$ is used to calculate the soot volume fraction. The soot model consists of two transport equations for the soot mass fraction and particle number density. The two transport equations include source terms to model the processes of nucleation, surface growth, coagulation and oxidation. The gas phase chemistry and soot reaction model are 
linked by considering acetylene as a soot precursor. The finite rate soot kinetics are included in a turbulent flame by prescribing the rate terms as functions of instantaneous mixture fraction. The mean rates can then be calculated by integrating the soot flamelets together with the $\beta$ pdf over instantaneous mixture fraction space. The accuracy of this model for turbulent propane flames has been demonstrated by Fairweather et al., [28] for preheated propane jet fires in pipe geometries.

\subsection{Boundary conditions and numerical parameters}

The system of transport equations are solved using a variant of the GENMIX algorithm for flows well approximated to be parabolic, [34].

In all of the simulations presented below the bulk inlet conditions are given by the nozzle diameter and the average source velocity. The mean stream-wise velocity distribution and radial velocity distribution are taken to be consistent with fully developed pipe flow, that is a $1 / 7^{\text {th }}$ power law is prescribed for the stream-wise velocity distribution and zero for the radial velocity component.

For all simulations in this article 40 control volumes in the radial co-ordinate direction spanning the jet radius are used to calculate the flame structure, with a maximum fractional step in the axial direction of less than $2 \%$ of the radial control volume spacing. A number of simulations using 80 control volumes were also completed to confirm that the predictions presented are independent of further mesh refinement. It is estimated that the predicted lift-off heights are within $2 \%$ of the fully mesh converged values.

\subsection{Visible radiation modelling}

The radiation intensity distribution to a receiver is modelled using a variant of the discrete transfer method, $[35,36]$. The orientations of characteristic rays within the field of view of the receiver are specified. The characteristic ray distribution is prescribed such that when projected onto a plane through the axis of the fire normal to the receiver orientation the rays form a line. Given the orientation and location of the receiver and the orientation of each characteristic ray, its path through computational space can be traced, to the edge of the domain. The incident 
intensity in the visible spectrum, $0.33-0.78 \mu \mathrm{m}$ is calculated by back tracking along the ray to the receiver solving the equation of radiation transfer in its differential form,

$$
\frac{d I_{\lambda}}{d s}=-K_{\lambda} I_{\lambda}+K_{\lambda} I_{b, \lambda}
$$

ignoring scattering. Ideally the spectral absorption coefficient should include the contribution from both the soot and participating species, however the calculation of the spectral line emission from gas molecules is a computationally challenging task compared to the continuous emission from the soot. No narrow or wide band approximations, [27, 37] are available to model emission in the visible spectral window, as all such models have been formulated for banded emission in the infrared range, $1-1,000 \mu \mathrm{m}$. Therefore the spectral absorption coefficient is based on soot emission alone,

$$
K_{\lambda}=\frac{7 s_{v f}}{\lambda}
$$

which has been used successfully to calculate radiation heat transfer in jet fires, [27]. The use of soot emission alone restricts the application of the model to fuels with a tendancy to produce soot such as propane or situations where soot production might be significant such as large scale subsonic methane jet fires, [17].

All the fire structure predictions were made on the basis of Reynolds-averaged mean temperatures and Favre averaged soot concentrations. The actual intensity of radiation emitted from a fluctuating turbulent flame can however exceed values estimated using mean scalar properties since the physical parameters controlling radiative heat transfer interact in a highly nonlinear fashion [38]. The augmentation of radiation by fluctuations about the mean temperature depends crucially on the root mean squared (RMS) temperature. Kritzstein and Soufiani [39] studied turbulence-radiation interaction in a homogeneous turbulent medium and demonstrated that for the configuration examined a relative RMS temperature of $10 \%$ meant that the relative difference in intensity calculated using the mean temperature and a stochastic simulation, which took the effects of turbulence fluctuations into account, was of the order of $8 \%$. If the relative RMS temperature was increased to $40 \%$, then the difference in intensity calculated by the two methods increased on average to $90 \%$. No RMS temperature measurements were made for the jet fires considered below. Hassan et al. [40] did take RMS temperature measurements in a methane jet flame of comparable size to the propane jet fires 
considered below and found an RMS temperature of approximately $170 \mathrm{~K}$ occurred on the flame axis at the same location as the peak mean temperature of $1700 \mathrm{~K}$, and in other regions of the flame the relative RMS temperature had a peak value of $20 \%$. It is therefore unlikely that turbulence-radiation interactions have a large effect on radiation heat transfer for the flames considered below if the change of fuel from methane to propane can be discounted. This is further supported by modelling studies of jet fires were the mean flame property approach has been in better agreement with measured radiation heat flux distributions than a stochastic approach modelling the turbulence-radiation interactions, [41]. The influence of turbulenceradiation interactions was therefore ignored.

\section{Description of the numerical algorithm}

When considering how a lifted flame differs from a rim-stabilised flame in the context of the mathematical model described above, the key difference is the composite probability of burning field

$$
\mathrm{P}_{\text {burn }}=\mathrm{P}_{\mathrm{b}} \mathrm{P}_{\mathrm{d}}
$$

In a rim-stabilised flame $P_{b u r n}$ is one everywhere, whereas in a lifted flame this takes a value between zero and one. Zero below the lift-off region, between zero and one in the lift-off region and one above it. Therefore an algorithm based on a "guess and correct" approach for the composite probability of burning field suggests itself as one way of extending a parabolic flow model suitable for simulating rim-stabilised jet fires to predicted lifted jet fires. To initialise the process some estimate of the composite probability of burning field must be prescribed. There are a number of possibilities, for example the fire could start off as being rim-stabilised, and hence the initial composite probability of burning field could be set to one everywhere. An alternative choice is to prescribe the jet to be isothermal, with a composite probability of burning of zero everywhere; both options have some appeal as in the initial rim-stabilised fire approach $\left(P_{b u r n, 0}=1\right)$, this is how a lifted jet fire would initiate, alternatively the analysis of Pitts [42] and Sanders and Lamers [26] work on isothermal jets indicates that the non-reacting isothermal region upstream of the flame base is important in the flame stabilisation process, favouring the second approach $\left(P_{b u r n, 0}=0\right)$. 
Once the composite probability of burning field is prescribed, an estimate of the flame structure can be calculated by running the parabolic flow model. As the flame structure is calculated flow fields required to estimate the lift-off height and the composite probability of burning field, such as the mean mixture fraction, mean temperature, turbulence kinetic energy, and the dissipation rate of the turbulence kinetic energy, are stored. Once the flame structure is complete, a new estimate of the lift-off height is calculated and the composite probability of burning field recalculated. If the change in lift-off height is small the algorithm is terminated otherwise the flame structure is recalculated and the process continues.

In the description given above there are a number of issues identified or statements made that require further clarification. Figure 1 shows the convergence history for two simulations. The mean lift-off height and relative change in mean lift-off height are plotted against the iteration number. The jet fire simulated is the same in each case, $\left(D=6.1 \mathrm{~mm}, U_{0}=31.6 \mathrm{~m} / \mathrm{s}\right)$, for each of the simulations the large-scale strain rate sub-model is used, with different initial composite probability of burning fields. In the convergence history labelled as 'hot' start the initial guess for the composite probability of burning is one everywhere. The convergence history labelled as 'cold' start the initial guess for the composite probability of burning is zero everywhere. Little sensitivity to the initial guess for the composite probability of burning is shown. The cold start simulation is marginally superior. For the first 10-11 iterations convergence is monotonic after which round-off error prevents further convergence. However the differences in predicted liftoff heights for successive iterations is less than $0.01 \%$ and changes of less than $1 \%$ are sufficient for the lift-off height to be converged to the visual resolution of Figure 1. Figure 1 suggests the algorithm takes around 5-6 iterations to converge. This was found to be typical behaviour for all of the jet fire simulations presented below. 
a)

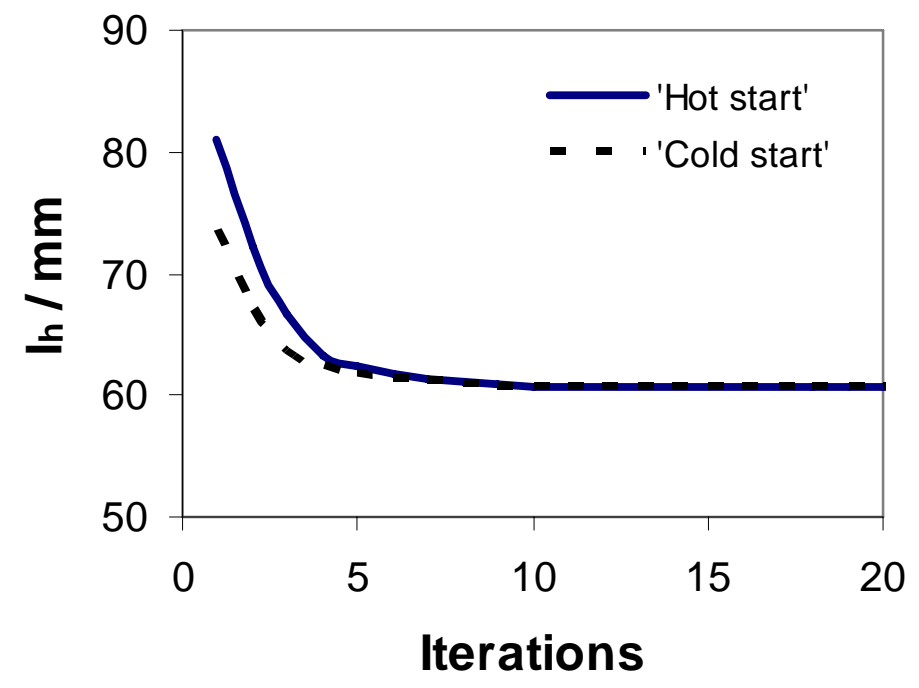

b)

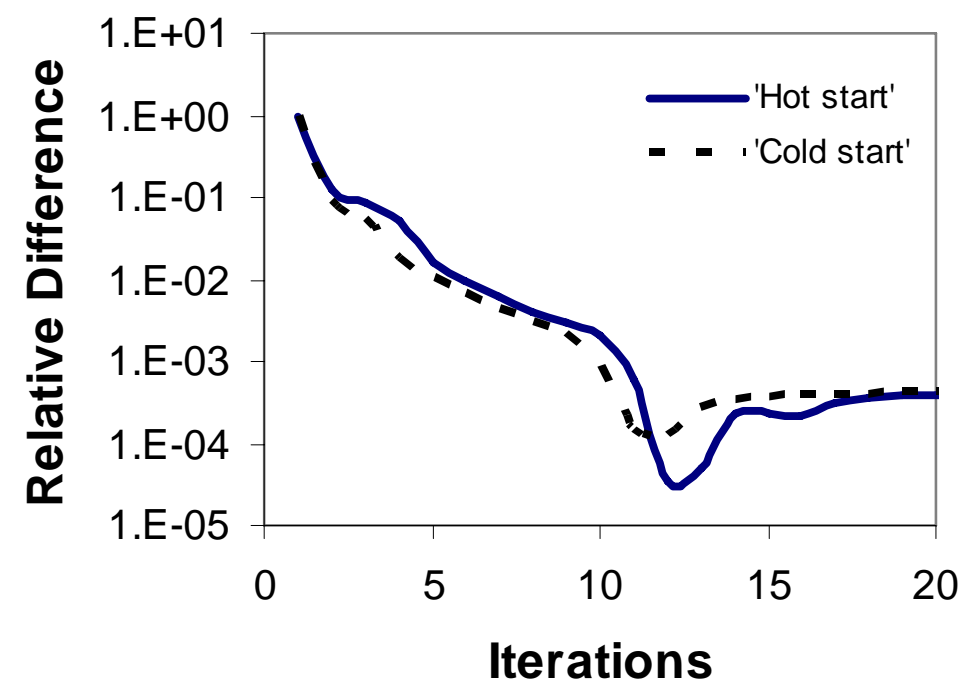

Figure 1. Convergence history for a lifted jet fire simulation, a) lift-off height and b) relative difference.

\section{Results}

\subsection{Flame structure model validation}

The soot model has been validated extensively in [28]; however before we consider the visible intensity field the use of an enthalpy perturbation based on the optically thin limit to account for the radiative heat loss from a propane jet fire is questionable given the propensity for soot 
generation in propane jet fires. In support of using the optically thin approximation this approach has been used successfully by Fairweather et al. [28]. To further improve confidence in this aspect of the model three propane jet fires studied by Becker and Yamazaki [43] were simulated and measured and predicted mean temperatures compared. The jet fires were rimstabilised by a small co-flow of hydrogen and had a diameter of $4.57 \mathrm{~mm}$. The source Reynolds numbers of the jet fires were 17,200, 41,300 and 58,300. Further details of the experimental set up can be found in [43]. Figure 2 shows the predicted and measured temperature distribution on the jet axis for three propane jet fires. The level of agreement between the measured and predicted temperature distributions is good in the two high Reynolds number jet fires; whereas for the lower Reynolds number jet fire the measured temperature is over-predicted in the far field. The poor agreement for the lower Reynolds number jet fire is likely to be due to the basis of the mathematical model breaking down as the Froude Number is 6,900 which is close to the limiting value of 5,000 where problems with non-convergence can be an issue as discussed further below. It should be noted that the level of agreement is better than in Jeng et al. [44] where radiative heat loss from the fire is accounted for by introducing a global fraction of heat radiated correction to the temperature flamelet profile.

Becker and Yamazaki's [43] jet fires are of a similar scale to the jet fires used in the model calibration and for some of the jet fires used in the model validation; however at some increased scale the optically thin limit will have less validity. When this occurs is difficult to determine and in the absence of any temperature measurements this approach for accounting for radiative heat loss can only be validated indirectly by comparing predicted and measured flame lengths. 
a)

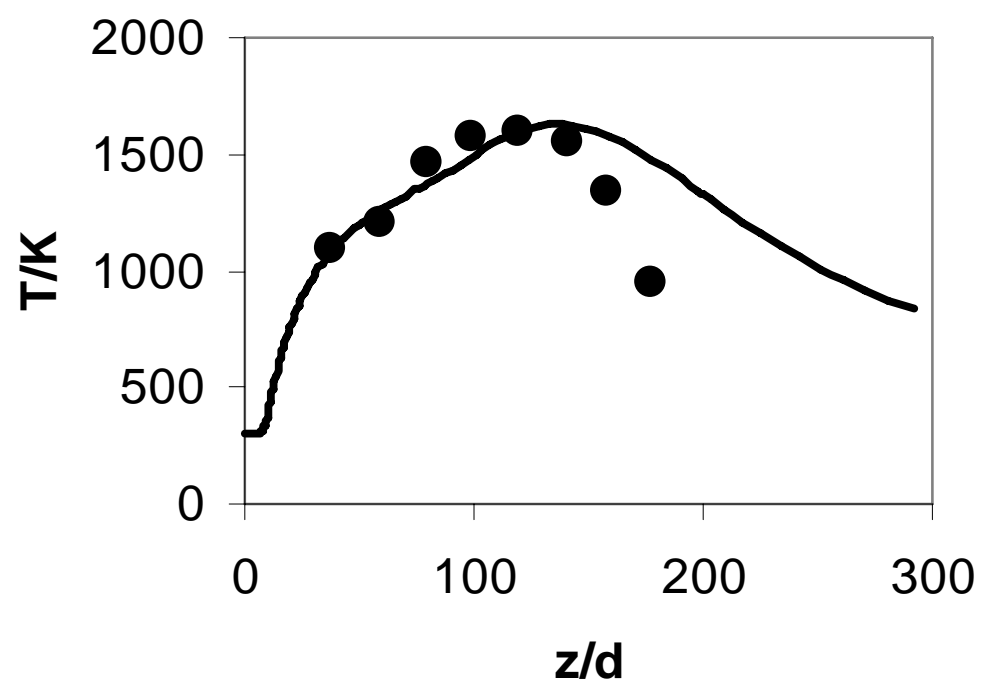

b)

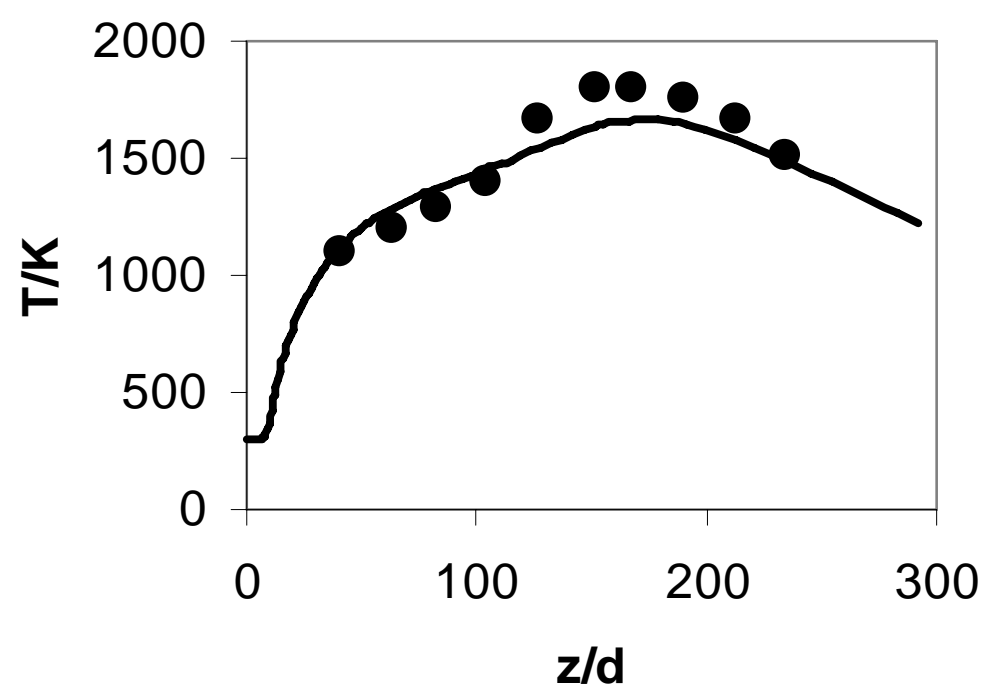

c)

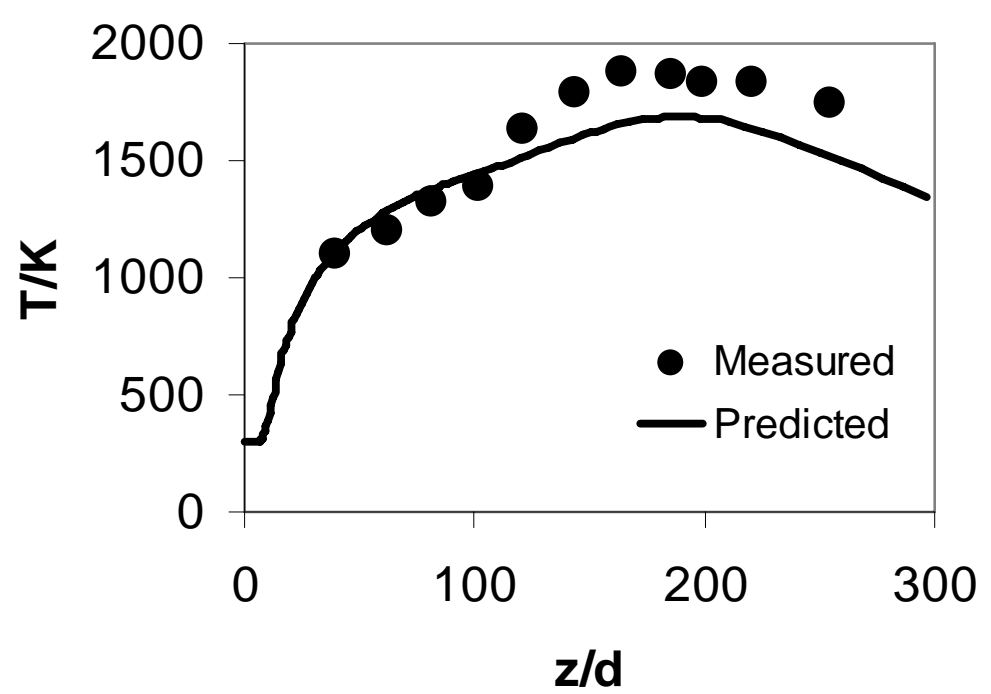

Figure 2. Temperature distribution on the axis of three propane jet fires, a) $\mathrm{Re}=17,200, \mathrm{~b}$ ) $\mathrm{Re}=41,300$ and $\mathrm{c}) \mathrm{Re}=58,300$. 


\subsection{Lift-off height model calibration}

Sanders and Lamers calibrated their model using Wittmer's measurements, [33] of lifted jet fires. For the propane jet fires of Kalghatgi, [6] the lift-off height model was calibrated by setting $C_{s, 2}$ to 3.33. Figure 3 shows a comparison of the predicted and measured lift-off height for a range of source velocities and source diameters of $6.1 \mathrm{~mm}$ and $4.03 \mathrm{~mm}$. The calibration constant was fixed by matching the predicted lift-off height of the jet fire, $D=6.1 \mathrm{~mm}$ and $U_{0}=31.6 \mathrm{~m} / \mathrm{sec}$, with the measured value. This is at the lower end of the lift-off height range. This jet fire was chosen as any degradation in agreement between the measured and predicted lift-off height tends to be amplified as the source velocity is increased. It can be seen that the lift-off heights insensitivity to source diameter is reproduced by the model. 
a)

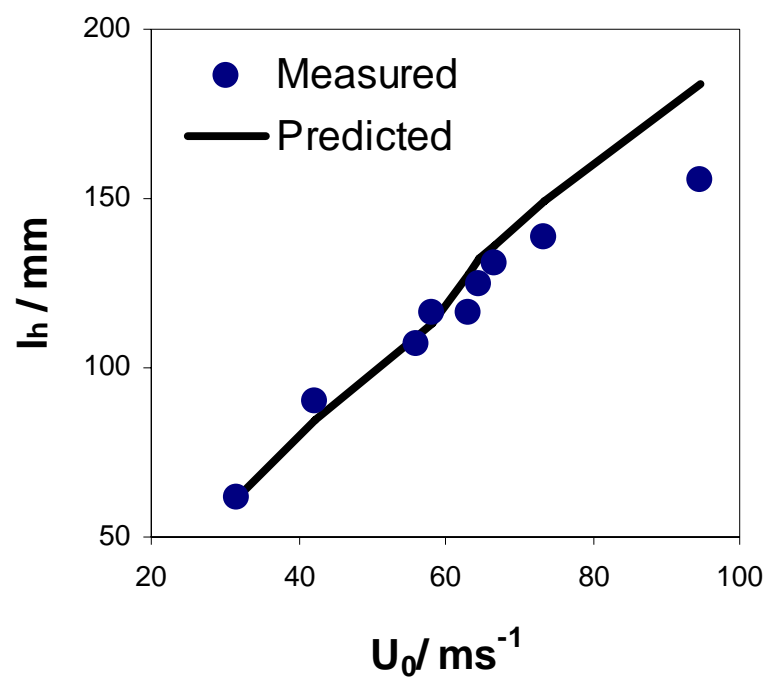

b)

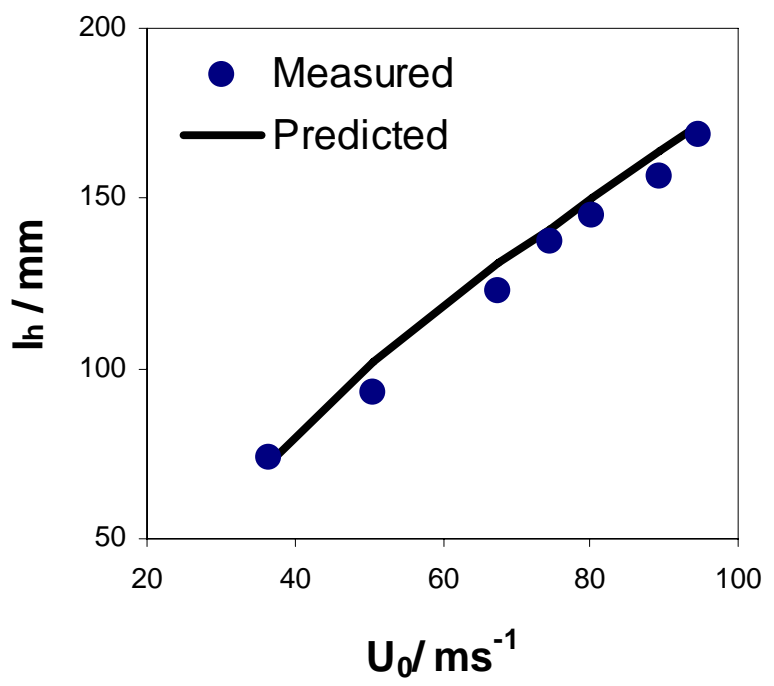

Figure 3. Predicted and measured lift-off heights for Kalghati's [6] propane jet fires, a) $D=6.1 \mathrm{~mm}$ and b) $D=4.1 \mathrm{~mm}$.

To demonstrate the robustness of the calibration determined above, a comparison of the model predictions of lift-off height with all of Kalghatgi's measurements for propane jet fires with a source diameter of $8.3 \mathrm{~mm}$ or less is reproduced in Figure 4. Jet fires with a larger source diameter were not included as the larger source diameter jet fires due to limitations of the experimental apparatus had a reduced source velocity and a corresponding reduced source Froude number, [6] to a point where the validity of the parabolic flow model was questionable. 
It can be seen in Figure 4 that with one exception all predicted jet fire lift-off heights are within $20 \%$ of the measured values. The average relative error is $7 \%$. The one point outside the $20 \%$ bracket is the jet fire with the lowest source Froude number considered.

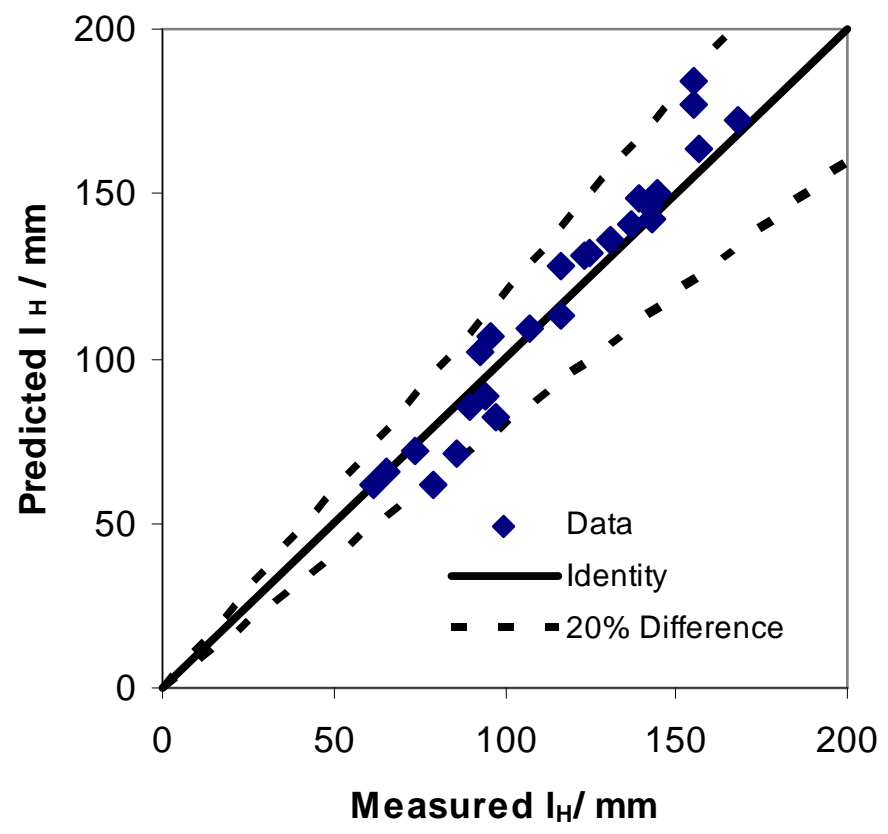

Figure 4. Comparison of measured and predicted lift-off heights for all of Kalghati's [6] propane jet fires, with Froude Numbers greater than 5,000.

It was found that for source Froude numbers below a threshold,

$$
F r=\frac{U^{2}}{g D}<5,000
$$

the numerical algorithm would sometimes not converge. This could always be cured by increasing the number of control volumes; however this was not done as it was taken as an indication of a loss of validity of the flow model basis.

\subsection{Flame structure prediction}

Having verified the temperature field prediction is acceptable to predict the visible intensity field for any given receiver the mean temperature and soot volume fraction fields are required. Figure 5 shows the predicted mean temperature and soot volume fraction field for the propane jet fire used to calibrate the lift-off model, $D=6.1 \mathrm{~mm}$ and $U_{0}=31.6 \mathrm{~m} / \mathrm{sec}$. The lift-off height is 
approximately 10 diameters. No measured flame length is available for comparison but Kalghatgi's flame length correlation, (8) suggests a flame length of the order of 190-200 diameters. Figure 6 shows the corresponding visible intensity field,

$$
I_{\text {vis }}=\int_{0.33}^{0.78} I_{\lambda} d \lambda
$$

a)

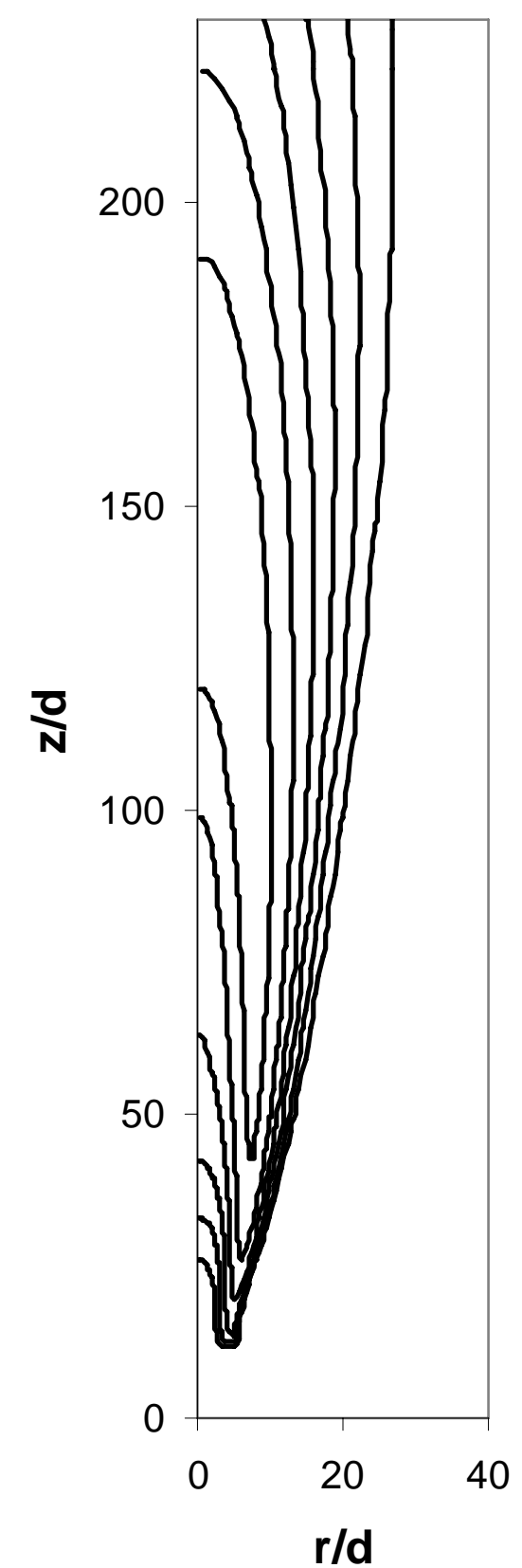

b)

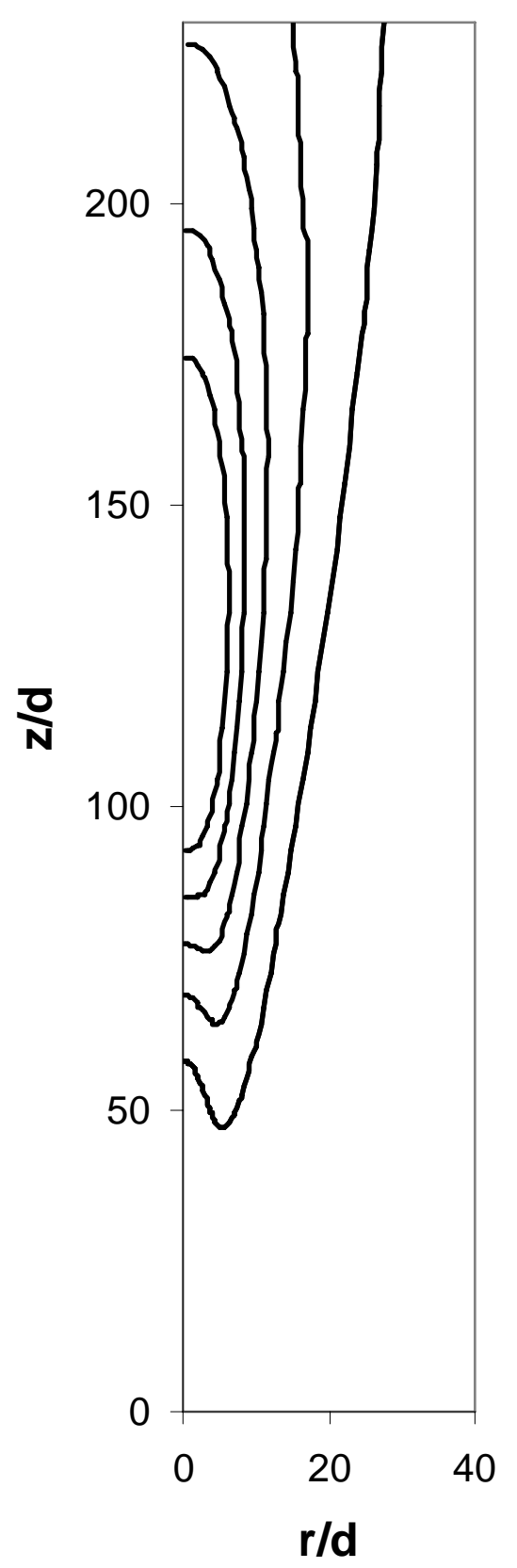

Figure 5. Flame structure of a lifted propane jet fire, $D=6.1 \mathrm{~mm}$ and $U_{0}=31.6$, a) Mean temperature field, contour values of $800 \mathrm{~K}$ to $1800 \mathrm{~K}$ step $200 \mathrm{~K}$ and b) Soot volume fraction with 5 contour values of 3.16E-7 to $1.58 \mathrm{E}-6$ step $3.16 \mathrm{E}-7$. 
calculated from the predicted flame structure in Figure 5. It should be stressed that the contours of visible intensity in Figure 6 are equi-logarithmically spaced, with contour values of 2.8, 7.9, $21,63,170$ and $440 \mathrm{~W} / \mathrm{m}^{2}$ str. The large range in the visible intensity field is due to the nonlinear dependence on temperature, as discussed above. In Figure 6 the visible intensity field was calculated for a receiver located at $(\mathrm{r}, \mathrm{z})=(0.5 \mathrm{~m}, 1 \mathrm{~m})$ with a horizontal orientation through the jet fire axis. For this receiver location the high intensity region is concentrated in a small portion of the field of view of the receiver. This is a characteristic feature of the external radiation fields of jet fires that causes the 'ray effect', [45] and requires special treatment in the numerical calculation of the radiation heat flux distribution, [46, 47]. Similarly for the visible intensity distribution a large number of characteristic rays are required to get a reasonable representation. In Figure 5 the ray distribution was calculated using the area conserving projection of the unit hemisphere defined by the angle of incidence, $\theta_{\text {Ray }}$ and angle of rotation, $\varphi_{\text {Ray }}$ of a characteristic ray,

$$
\begin{aligned}
& X=\theta_{\text {Ray }} \cos \varphi_{\text {Ray }} \\
& Y=\theta_{\text {Ray }} \sin \varphi_{\text {Ray }}
\end{aligned}
$$

Ray directions are specified implicitly from mesh points $N_{X}$ by $N_{Y}$ points defined in $X, Y$ space. The ray direction in spherical co-ordinates is calculated by inverting the transformation (30) and (31). An advantage of specifying ray orientations in this way is it is relatively simple to restrict the ray orientations to those that pass through or near the flame envelope. In Figure 6 two hundred rays are used over the field of view of the receiver where the visible intensity field exceeds the ambient intensity. 


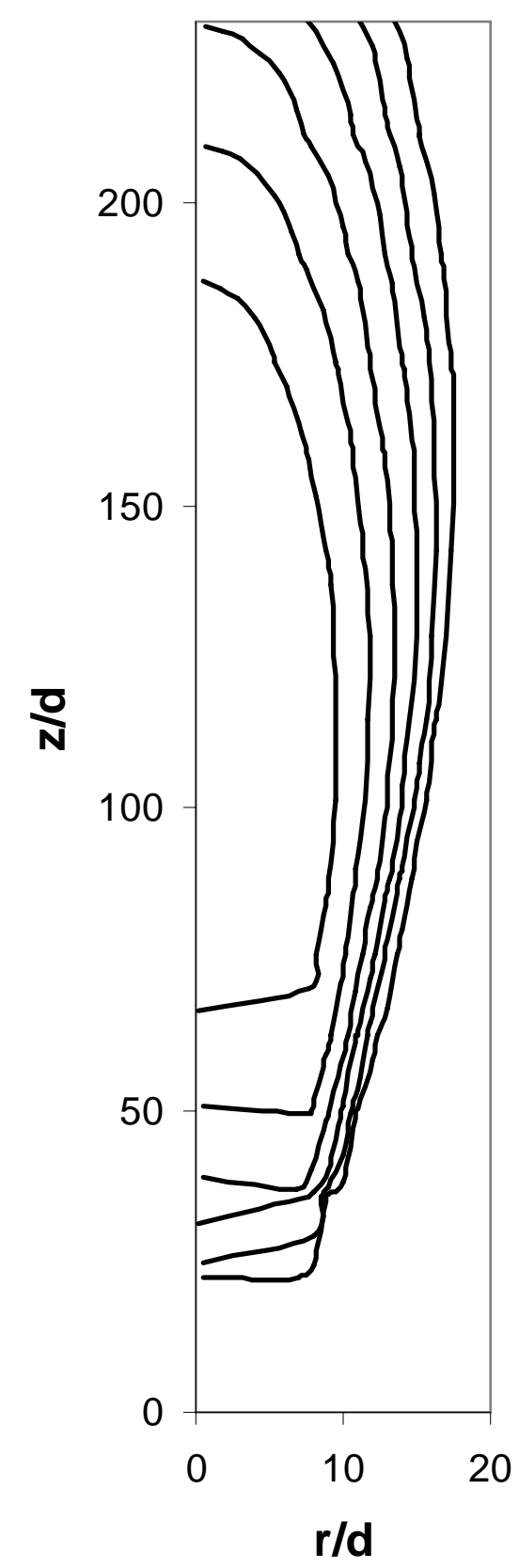

Figure 6. The visible intensity field projected onto the jet fire axis normal to the receiver orientation, contour values of $2.8,7.9,21,63,170$ and $440 \mathrm{~W} / \mathrm{m}^{2}$ str.

\subsection{Flame Length Sensitivity to Receiver Location}

When considering a flame length methodology it is important to assess the flame length sensitivity to the receiver location. Ideally the perceived flame length should be insensitive to receiver location and orientation, provided the flame envelope is in the field of view of the receiver. As the flame length is dependent on the visible radiation intensity Figure 7 shows the projected visible radiation intensity as a function of axial location, for the jet fire, $D=6.1 \mathrm{~mm}$ and 
$U_{0}=31.6 \mathrm{~m} / \mathrm{sec}$ for four receiver locations. All four receivers have a horizontal orientation directed towards the jet fire axes and are located at a height of $0.5 \mathrm{~m}$ above the source nozzle. The radial co-ordinates of the receivers are $0.3 \mathrm{~m}, 1 \mathrm{~m}, 3 \mathrm{~m}$ and $10 \mathrm{~m}$. The figure shows that the projected visible intensity distribution projected onto the jet fire axis sensitivity to receiver location is small. For example increasing the radial co-ordinate of the receiver from $0.3 \mathrm{~m}$ to $10 \mathrm{~m}$ changes the maximum visible radiation intensity by approximately $7 \%$. However the receiver must be sufficiently far from the flame such that characteristic rays passing through the flame tip are not too close to being nearly parallel with the jet fire axis. One measure of this is the scalar product of the ray orientation and the unit vector along the jet axis.

$$
\begin{aligned}
& n_{\text {Ray }} \cdot n_{z}=0 \Rightarrow \text { Vectors are orthogonal } \\
& n_{\text {Ray }} \cdot n_{z}=1 \Rightarrow \text { Vectors are parallel }
\end{aligned}
$$

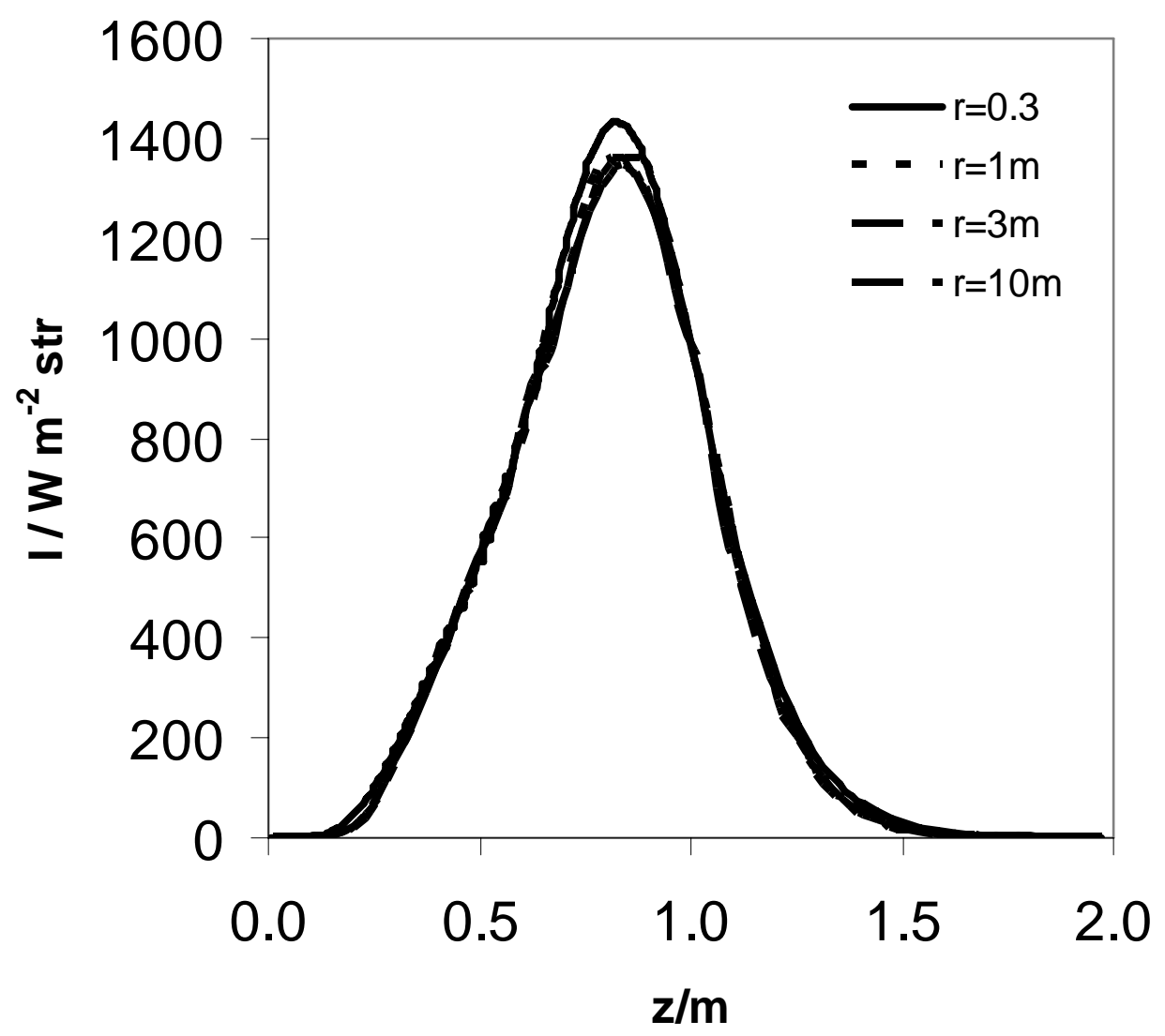

Figure 7. 'Visible' radiation intensity projected onto the jet fire axis for a number of receiver locations, $D=6.1 \mathrm{~mm}$ and $U_{0}=31.6$.

The projected visible intensity distributions and the location of the receiver closest to the fire in Figure 7 suggests that provided,

$$
n_{\text {Ray }} \cdot n_{\mathrm{z}}<0.92
$$


and the receiver has a height of approximately half the flame length, the receiver is sufficiently far from the fire for the visible intensity projection step to be insensitive to the receiver location. In addition to considering the sensitivity of the projected visible intensity field to the receiver location it is of interest to consider flame length sensitivity to receiver location. Defining the flame length as,

$$
f_{L}=\underset{z}{\arg }\left\{I_{v i s}(z)=40 \mathrm{~W} / \mathrm{m}^{2} s t r\right\}
$$

the flame length as a function of receiver location can be analysed. The justification for this definition of flame length will be considered below. Figure 8 shows the flame length for the four receiver locations considered in Figure 7. The flame length range is $1.4-1.5 \mathrm{~m}$ for the receiver locations in Figure 7. The perceived increase in the flame length as the receiver approaches the jet axis is due to rays passing through the flame tip having a relatively longer path through the high temperature portion of the flame, than for rays from receivers further away. For receivers with a radial co-ordinate of $1 \mathrm{~m}$ or more the flame length predicted using (35) is insensitive to further increases in the radial co-ordinate. An appropriate scale to use is the flame length. For receivers approximately one or more flame lengths from the jet fire axis the predicted flame length is insensitive to the receiver location.

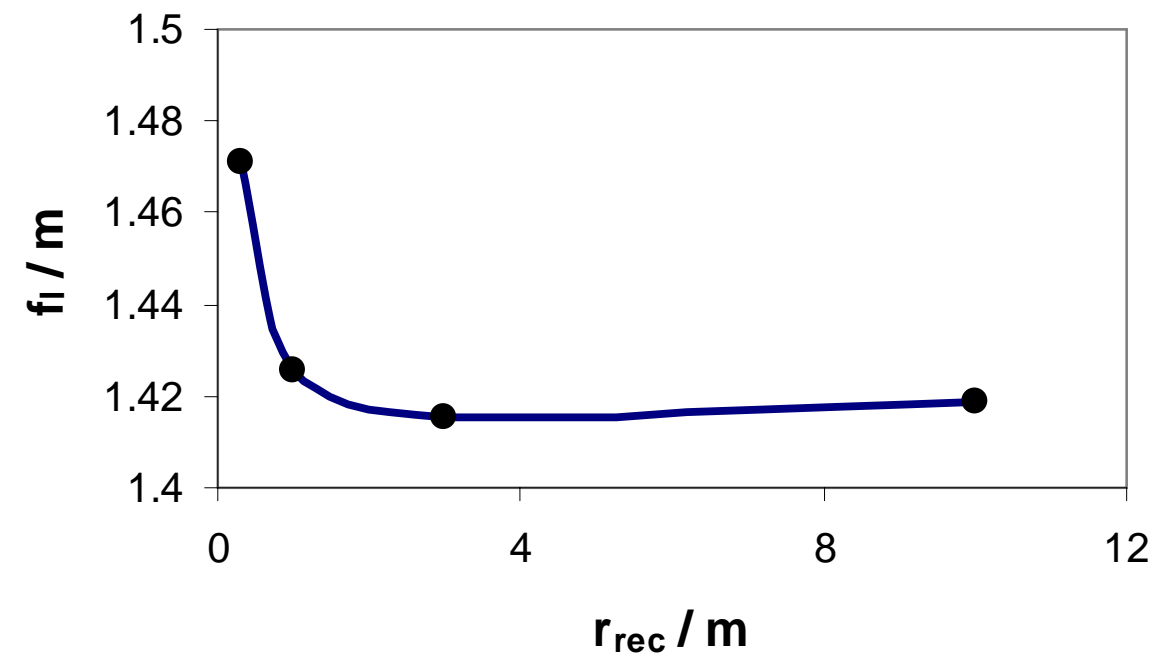

Figure 8 . Flame length sensitivity to camera location, $D=6.1 \mathrm{~mm}$ and $U_{0}=31.6$. 


\subsection{Flame length methodology calibration}

The flame length is determined as a function of the projected visible intensity field. Therefore to complete the methodology a value for the visible intensity that represents the flame boundary must be specified. Becker and Liang's, [5] propane jet fires are used to calibrate the methodology. Using the high source Froude number jet fires,

$$
\operatorname{Fr}>30,000
$$

to calibrate the flame length methodology a value of $40 \mathrm{~W} / \mathrm{m}^{2}$ str for the visible intensity is found to give a reasonable approximation to the visible flame boundary. Figure 9 shows a comparison of the flame length methodology with Becker and Liang's measurements, [5]. The source diameter of the jet fires in Figure 9 is $4.57 \mathrm{~mm}$. The good agreement is encouraging but only an indication of the quality of the model calibration. The rapid variation of the projected visible intensity with changing height means the predicted flame length is not overly sensitive to the value of the visible intensity used to define the flame length. Figure 10 shows the predicted flame length for three visible intensity values spanning two orders of magnitude. Quantifying the sensitivity, reducing the visible intensity used to define the flame length from $40 \mathrm{~W} / \mathrm{m}^{2}$ str to $4 \mathrm{~W} / \mathrm{m}^{2}$ str tends to increase the predicted flame length by typically less than $15 \%$.

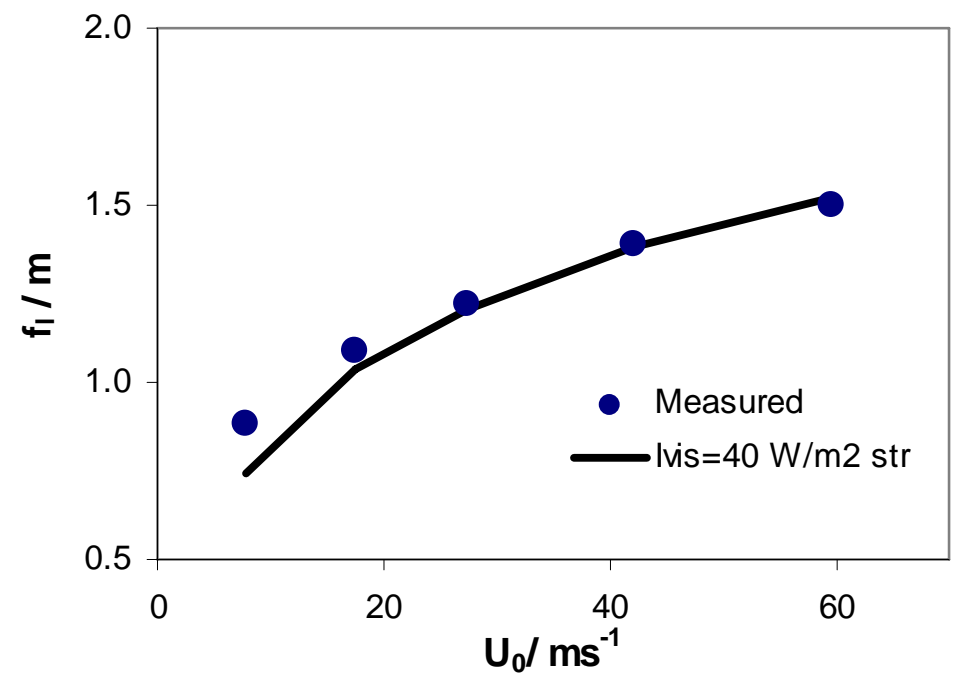

Figure 9. Calibration of the flame length methodology using Becker and Liang's [5] jet fire measurements. 


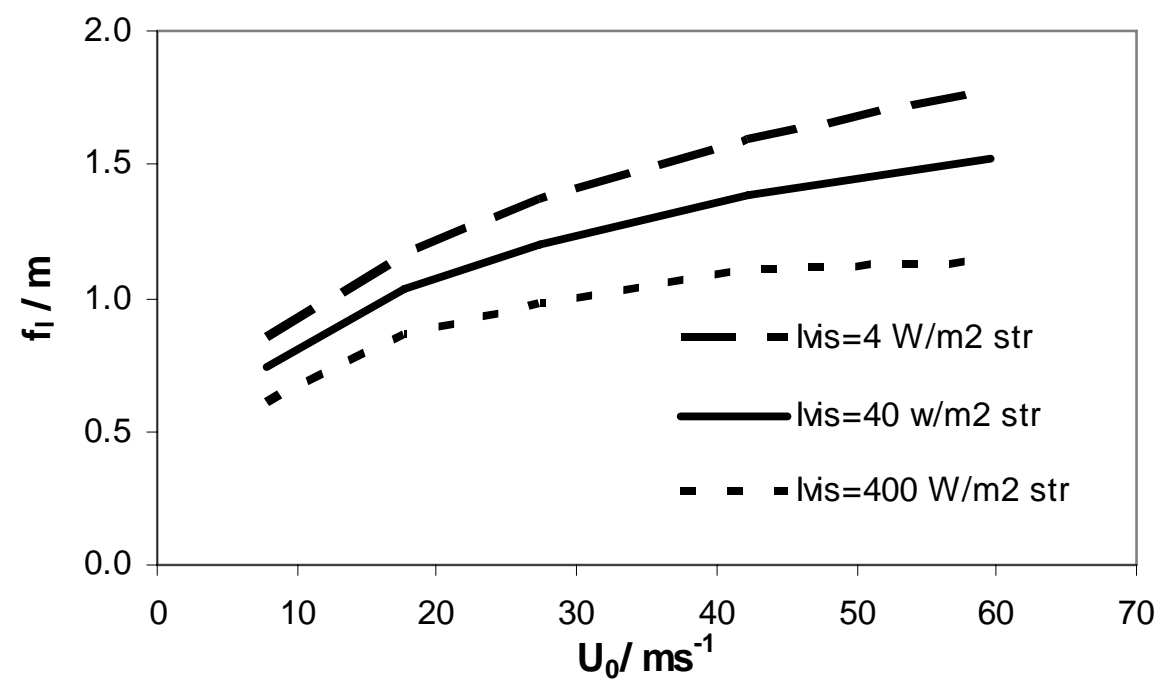

Figure 10. Flame length sensitivity to the intensity used in the flame length methodology calibration.

\subsection{Flame length Methodology Validation}

In this section the accuracy of the flame length methodology is considered further by comparing predicted flame lengths with the measurements of Sugawa and Sakai, [9] and Sonju and Hustad [10]. Sugawa and Sakai, [9] considered a range of source diameters, source velocities and lifted and rim-stabilised jet fires. Sugawa and Sakai measured the mean flame length using a video system, averaging 90 images, compared to Becker and Liang, [5], who averaged 3 photographic images. Figure 11 shows a comparison of the predicted and measured flame lengths for a subset of Sugawa and Sakai [9] measurements. Jet fires with source diameters of $9.1 \mathrm{~mm}, 12.7 \mathrm{~mm}$ and $16.1 \mathrm{~mm}$ are presented in Figure 11 as there are sufficient measurements to produce a reasonable trend in measured flame length with increasing source velocity. The agreement between the methodology and the experiments is acceptable given the differences in the experimental set up of Sugawa and Sakai [9] and Becker and Liang, [5]. Sugawa and Sakai [9] duplicated a number of their experiments giving an indication of repeatability. The jet fires with a source diameter of $9.2 \mathrm{~mm}$ exhibiting relatively poor repeatability, with nominally the same experimental conditions giving measured flame lengths with a relative difference of the order of $30 \%$. For the larger source diameters the repeatability is much improved. The reason for this behaviour is unclear. 
Figure 12 is a comparison of predicted and measured flame lengths for all of Sugawa and Sakai's [9] data and Becker and Liang's data, including the jet fire data not used in the methodology calibration. The average relative difference between the predicted flame length and measured flame length is $7 \%$. A significant influence on the level of agreement achieved is the degree of repeatability exhibited in Sugawa and Sakai's experiments.

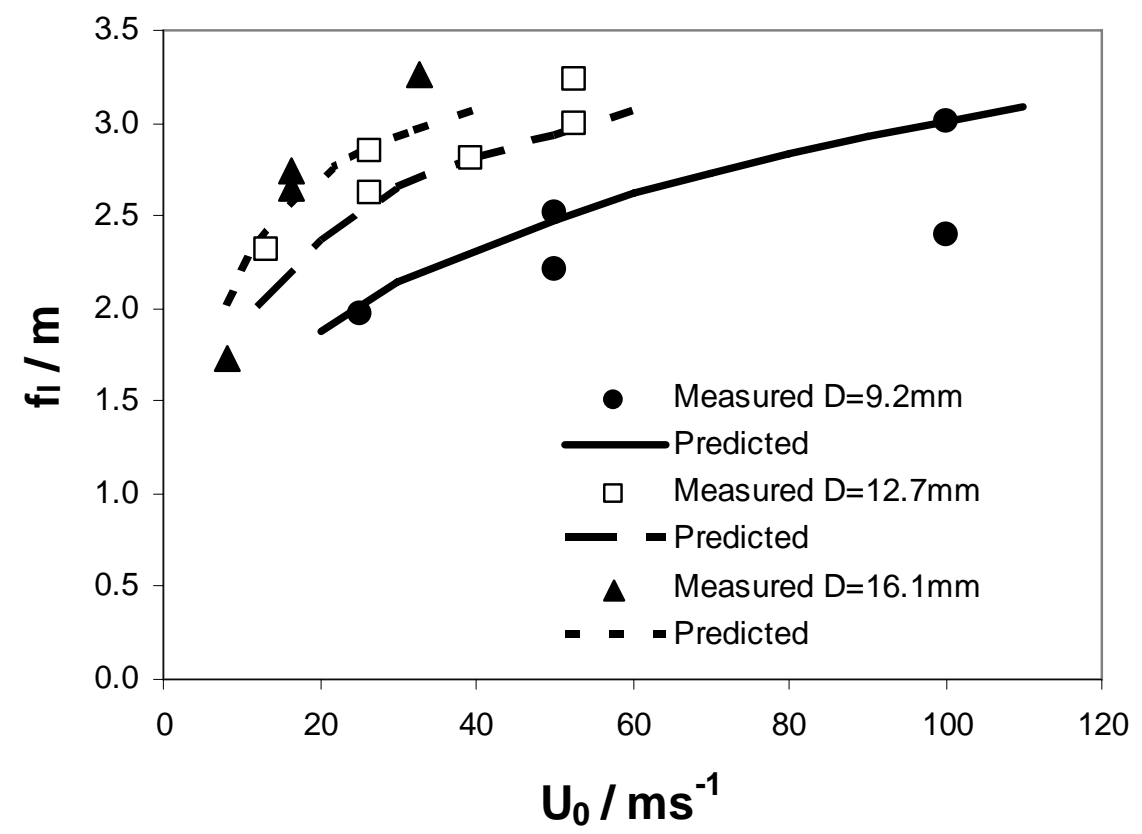

Figure 11. A sample of the validation of the flame length methodology using Sugawa and Sakai's [9] measurements.

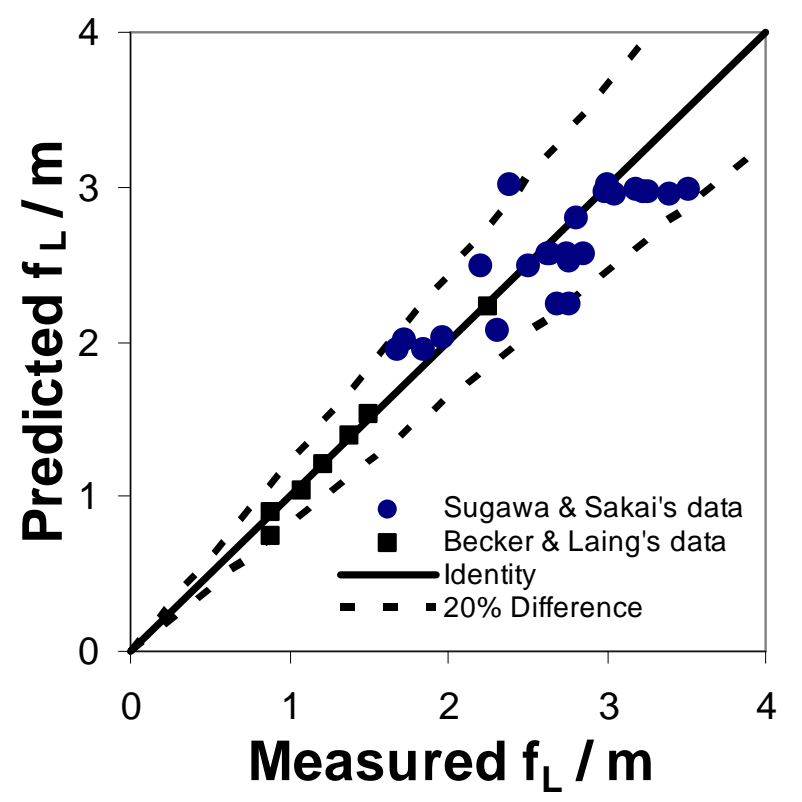

Figure 12. Comparison of measured and predicted flame lengths for Becker and Liang's and Sugawa and Sakai's [9] propane jet fires. 
Sugawa and Sakai's fires are marginally larger than Becker and Liang's in that the flame lengths are in the region of 2-3 metres compared to 1-2 metres long. However they are sufficiently close to Becker and Liang's experiments that more validation of the flame length methodology at a larger scale is of interest. To validate the flame length methodology further, the propane jet fire measurements of Sonju and Huskad [10] are considered below. Sonju and Huskad measured flame lengths in propane jet fires for a range of nozzle diameters, $10 \mathrm{~mm}-80 \mathrm{~mm}$ and a range of Froude numbers, 80 - 600,000. Their measurements are presented in [10] in the form of a dimensionless flame length vs. Froude number. Unfortunately insufficient information is given to relate each individual flame length measurement to the nozzle diameter to fully determine source conditions. The lower Froude Number jet fires correspond to the larger nozzle diameter, $80 \mathrm{~mm}$ and the higher Froude number jet fires have a nozzle diameter of $10 \mathrm{~mm}$. This is imposed by the limitations of the experimental apparatus, specifically the large mass flow rates necessary to achieve large Froude numbers at the larger nozzle diameters. The parabolic flow model is not suitable for simulating low Froude number fires so only predictions of fires with a Froude Number of 1,000 or more are considered. Figure 13 shows a comparison of all of Sonju and Huskads flame length measurements with predictions of flame length calculated with a nozzle diameter of $10 \mathrm{~mm}$ and $20 \mathrm{~mm}$. The predicted flame lengths calculated with a nozzle diameter of $10 \mathrm{~mm}$ can be considered particularly relevant to the high Froude number jet fires; whereas the predicted flame lengths calculated with a nozzle diameter of $20 \mathrm{~mm}$ are more representative of mid-range Froude Numbers, 1,000 - 100,000. The jet fires with a nozzle diameter of $80 \mathrm{~mm}$ are not considered here as the Froude numbers are too low for the parabolic flow model to simulate the flame structure successfully. Overall the agreement should be considered reasonable as the predicted flame lengths where the nozzle diameter used in the simulations is most representative are within the variation in the measured flame lengths. The large degree of scatter in the measurements is partly due to the different nozzle diameters used. Considering the jet fire simulations using the $10 \mathrm{~mm}$ diameter nozzle, there is a tendency for the calculated flame length to over predict the measured data. Sonju and Huskad [10] recognised that their experimental jet fires tended to give smaller flame lengths proportionate to the nozzle diameter than other experimental studies, they believed the reason was the difference in scale as they measured flame lengths of 1-8m although this has not been identified as an issue in comparable large-scale methane jet fire experiments, [48]. Heskestad [4] also found that Sonju and Huskad's flame length measurements were below the flame lengths calculated using the correlation (4). Heskestad suggested that another possible mechanism for the reduced flame length is the 
influence of the atmospheric boundary layer on the flame dynamics. This is consistent with Cetegen et al's. [49] observations of laboratory-scale flames subjected to disturbances.

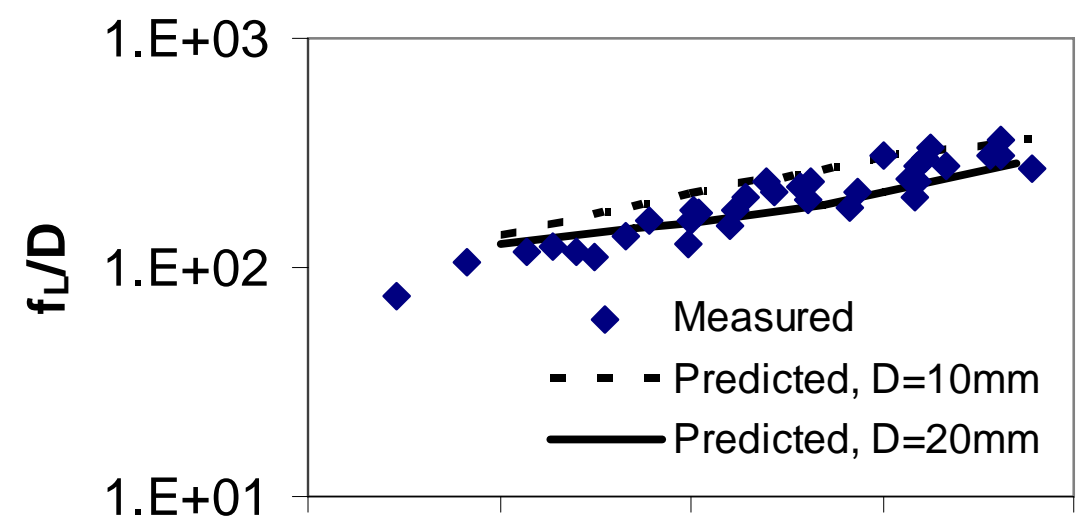

\section{E+02 1.E+03 1.E+04 1.E+05 1.E+06}

$\mathrm{Fr}$

Figure 13. Comparison of predicted and measured dimensionless flame length for Sonju and Hustad's [10] propane jet fires.

\section{Conclusion}

The calculation of flame lengths is an important characterisation of a jet fire when assessing the safety of high pressure plant processing flammable materials. In this article a flame length methodology has been presented that mimics the human eye or camera. The methodology relies on a CFD framework to calculate the flame structure. This has a number of advantages over a dimensionless group/ correlation or a flame length definition based on some measure of combustion completeness. The main advantage is the methodology can be extended to other types of fire relatively easily provided the basis of the CFD flow model is sufficiently general. It is also possible to include the influence of the atmospheric boundary layer with ease and a change of scale from laboratory to field-scale fires as the accuracy of CFD based fire models is insensitive to scale.

To extend the range of measurements available for validation and calibration purposes the parabolic flow model was extended to predict both rim-stabilised and lifted jet fires. The flame length methodology was calibrated using Becker and Liang's jet fires [5] except where the source Froude number was too low for the parabolic flow model to be valid. The methodology 
was validated using the jet fire measurements of Sugawa and Sakai [9] and Sonju and Hustad [10]. Good agreement over a range of scales was demonstrated particularly when taking the degree of repeatability of the experiments into account.

One weakness of the flame length methodology is radiation emission in the visible spectral window is assumed to be due to soot alone. One reason for this is all banded models for calculating emission from participating species tend to be formulated for emission in the infrared spectral window. Calculation of the line emission in the visible spectral window is a significant task that would dominate the computations of the flame structure, disproportionately to its significance. For fuels with a tendency to produce significant soot concentrations this is not an unreasonable assumption. Therefore the methodology is expected to be applicable to field-scale subsonic methane jet fires, [48] but requires extension to include gas emission for laboratoryscale methane jet fires.

The extension of the flame length methodology to other fire regimes requires either a recalibration or an extension to include emission from participating species. As well as extending the methodology to other fires, it could also be used to calculate flame volumes. A further application would be the computer animation of turbulent flames as part of a virtual reality simulation of fires for fire fighting training purposes.

\section{Acknowledgements}

This research was undertaken while Dr Peter Cumber was on a research visit to the Department of Civil Engineering, University of Canterbury, Christchurch, New Zealand. He would like to thank the Royal Academy of Engineering for the Global Research Award and the EPSRC for the Overseas travel Grant, GR/T22735 that made this secondment possible. 


\section{References}

1. Cleaver RP, Cumber PS, Fairweather M. Predictions of free jet fires from high pressure, sonic releases. Combust Flame 2003; 132: 463-474.

2. Roberts TA. Effectivness of an enhanced deluge system to protect LPG tanks and sensitivity to blocked nozzles and delayed deluge initiation. J Loss Prev Process Ind, 2004; 17: 151-158.

3. Heskestad G. Luminous heights of turbulent diffusion flames. Fire Safety J, 1983; 5: 103-108.

4. Heskestad G. Turbulent jet diffusion flames: consolidation of flame height data. Combust Flame, 1999; 118: 51-60.

5. Becker HA, Liang D. Visible length of vertical free turbulent diffusion flames. Combust Flame, 1978; 32: 115-137.

6. Kalghatgi GT. Lift-off heights and visible lengths of vertical turbulent diffusion flames in still air. Combust. Sci Tech, 1984; 41: 17-29.

7. Hawthorne WR, Weddell DS, Hottel HC. Mixing and combustion in turbulent gas jets . $3^{\text {rd }}$ Symp. (Int.) Combust, Williams and Wilkins, Baltimore, 1949, p266-288.

8. Drysdale D. Introduction to Fire Dynamics, $2^{\text {nd }} \mathrm{Ed}^{\mathrm{n}}$, Wiley, UK, 1998.

9. Sugawa O, Sakai K. Flame length and width produced by ejected propane gas fuel from a pipe. $13^{\text {th }}$ Meeting of the UJNR Panel on Research and Safety, NISTIR 6030, 1997, p 401-411.

10. Sonju OK, Hustad J. An experimental study of turbulent jet diffusion flames, $9^{\text {th }}$ ICODERS, Poitiers, France, 1983, AIAA, 1984.

11. Cook DK, Fairweather M, Hammonds J, Hughes DJ. Size and radiative characteristics of natural gas flares. Part 1 - field-scale experiments. Chem Eng Res Des, 1987; 65: 310-317, 1987.

12. Brzustowski TA, Sommer EC. Predicting radiant heating from flares. Proc. Div ${ }^{\mathrm{n}}$ of Refining A.P.I.,1973; 53: 865-893.

13. Hottel HC. "Fire Modelling", International Symposium on the use of fire models, Ed. WG Berl, Publication 746, National Academy of Science, National Research Council, Washington D.C., 1961.

14. Wade R, Gore JP. Visible and chemical flame lengths of acetylene/ air jet diffusion flame, NIST, NISTR 5904, 1996, p 41-42.

15. Newman JS, Wieczorek CJ. Chemical flame heights. Fire Safety J, 2004; 39: 375382. 
16. Orloff L, de Ris J, Delichatsios MA. Chemical modelling of gaseous species in turbulent fires, FM Global Technical Report, FMRC J.I. OK0J2.BU, 1985.

17. Fairweather M, Jones WP, Lindstedt RP. Predictions of radiative transfer from a turbulent reacting jet in a cross-wind. Combust Flame, 1992; 89: 45-63.

18. Ballie S, Caulfield M, Cook DK, Docherty P. A phenomenological model for predicting the thermal loading to a cylindrical vessel. Process Safety and Environmental Protection, 1998; 76: 3-13.

19. Fairweather M, Jones WP, Lindstedt RP, Marquis AJ. Predictions of a turbulent reacting jet in a cross-flow. Combust Flame, 1991; 84: 361-375.

20. Siegel R, Howell JR. Thermal Radiation Heat Transfer, $3^{\text {rd }}$ Edition, Hemisphere Publishing Corporation, 1992.

21. Mason P. Estimating thermal radiation fields from 3D flame reconstruction. Masters Thesis, Lincoln University, New Zealand, 2003.

22. Pope SB. An explanation of the turbulent round-jet/ plane-jet anomaly. AIAA J, 1978; 16: 279-281.

23. Jones WP, Musonge P. Closure of the Reynolds stress and scalar flux equations. Phys Fluids, 1988; 31: 3589-3604.

24. Moss JB, Stewart CD, Syed K. Flow field modelling of soot formation at elevated pressure, $22^{\text {nd }}$ Symp (Int) Combust, pp. 413-423, The Combustion Institute, Pittsburgh, 1988.

25. Hossain MS, Rodi W. Influence of buoyancy on the turbulence intensities in horizontal and vertical jets, Heat transfer and buoyant convection, Edited by D.B. Spalding and N. Afgan, Hemisphere publishing corporation, Washington, 1976, Vol. 1, 39-51.

26. Sanders JPH, Lamers APGG. Modeling and calculation of turbulent lifted diffusion flames. Combust Flame, 1994; 96: 22-33.

27. Cumber PS, Fairweather M, Ledin S. Application of wide band radiation models to non-homogeneous combustion systems. Int J Heat Mass Transfer, 1998; 41: 1573-1584.

28. Fairweather M, Jones WP, Ledin S, Lindstedt P. Predictions of soot formation in turbulent non-premixed propane flames, Twenty Fourth Symp (Int) Combust, pp. 1067-1074, The Combustion Institute, Pittsburgh, 1992.

29. Chase MW, Davies CA, Downey JR, Frurip DJ, McDonald RA, Syverud AN. 1985, JANAF Thermochemical Tables, $3^{\text {rd }}$ Edition Journal Physical and Chemical Reference Data, 14, 1985. 
30. Peters N, Williams FA. Lift-off characteristics of turbulent jet flames. AIAA, 1983; 21: 423-429.

31. Horch, K., PhD thesis, Universitat Karlsruhe, Germany, 1978.

32. Cumber PS. Spearpoint M. Modelling lifted methane jet fires using the boundary layer equations. Accepted by the Journal of Numerical Heat Transfer, Part B.

33. Wittmer, PhD thesis, Universitat Karlsruhe, Germany, 1980.

34. Spalding DB. GENMIX: A general computer program for two-dimensional parabolic phenomena, Pergamon Press, Oxford, 1977.

35. Lockwood FC. Shah NG. A new radiation solution method for incorporation in general combustion prediction procedures. $18^{\text {th }}$ Symp (Int) Combust, pp. 14051414, The Combustion Institute, Pittsburgh, 1981.

36. Cumber PS. Improvements to the discrete transfer method of calculating radiative heat transfer. Int J Heat Mass Transfer, 1995; 38: 2251-2258.

37. Grosshandler WL. Radiative heat transfer in non-homogeneous gases: A simplified approach. Int J Heat Mass Transfer, 1980; 23:1447-1457.

38. Cox G. On radiant heat transfer from turbulent flames. Combust Sci Tech., 1977; 17: $75-78$

39. Kritzstein F. Soufiani A. Infrared gas radiation from a homogeneously turbulent medium. Int J Heat Mass Transfer, 1993; 36: 1749-1762.

40. Hassan MMA. Lockwood FC, Moneib HA. Fluctuating temperature and mean concentration measurements in a vertical turbulent free jet diffusion flame. La Rivista dei Combustibili, 1980; 38: 357-372.

41. Jeng SM, Lai MC, Faeth GM. Nonluminous radiation in turbulent buoyant axisymmetric flames. Combust Sci Tech, 1984; 40: 41-53.

42. Pitts WM. Importance of isothermal mixing processes to the understanding of liftoff and blowout of turbulent jet diffusion flames. Combust Flame, 1989; 76: 197212.

43. Becker HA, Yamazaki S. Entrainment, momentum flux and temperature in vertical free turbulent diffusion flames. Combust. Flame, 1978; 33: 123-149.

44. Jeng SM. Chen LD Faeth GM. An investigation of axisymmetric buoyant turbulent diffusion flames. Report prepared for National Bureau of Standards, Grant No. 7-9020, 1981.

45. Chai JC. Lee, HS. Patankar SV. Ray effect and false scattering in the discrete ordinates method. Numerical Heat Transfer, Part B, 1993; 24:373. 
46. Cumber PS. Ray effect mitigation in jet fire radiation modelling. Int J Heat Mass Transfer, 2000; 43: 935-943.

47. Cumber PS. Application of adaptive quadrature to fire radiation modelling. ASME, J Heat Transfer, 1999; 121:203-205, 1999.

48. McCaffrey BJ Evans DD, Very large methane jet diffusion flames, $21^{\text {st }}$ Symp (Int) Combust, pp. 25-31, The Combustion Institute, Pittsburgh, 1986.

49. Cetegen BK. Zukoski EE. Kubota T. Entrainment into the near and far field of fire plumes. Combust Sci Tech, 1984; 39:305-331. 